\title{
Second-generation Persians' Participation in the Oklahoma Dialect
}

\author{
Shima Dokhtzeynal \\ Oklahoma State University
}

Vowel systems are a rich source of information about speakers' social affiliations and linguistic influences. With the purpose of contributing to recent dialect investigations of immigrant communities inside the US, this study examined the acoustics of bilingual Persian-Oklahomans and their participation in Oklahoma dialect features. Twenty Oklahoma-born second-generation Persian-Americans were compared to ten monolingual EuropeanOklahomans with respect to their production of local dialect features. Results showed similar vowel spaces between the groups indicating that second-generation Persian-Oklahomans participated in the local mix of Southern and Midland features, with one notable exception: they did not display the PIN/PEN merger, a feature of Southern dialects. Similar studies on European-Oklahoman speakers suggested a uniform presence of PIN/PEN merger among Research on the Dialects of English in Oklahoma (RODEO) project respondents. However, PersianOklahomans' productions of these vowels were consistently unmerged across the continuum of speech styles. Accordingly, this study argues for a connection between this acoustic variation and speakers' demographic traits, make-up of social network, and heritage Farsi despite their frequent contact with the merger and their rich social network with middle-class European-Oklahoman speakers of the Oklahoma dialect.

\section{Introduction}

In recent years, rising levels of immigration have resulted in linguistic diversity in many major areas in the United States. Communities where languages other than English (LOTE) are spoken are the sites of contact between American English varieties and the LOTE (Bayley 2017). The purpose of this study is to investigate a situation of 'dialects in contact' (Trudgill 1986), especially dialects in contact 'across language boundaries' (Preston et al. 2009). A growing body of work on English vowel production of ethnic minorities has revealed both assimilation and resistance to assimilation to the local speech norms (e.g., Bakos 2012; Dubois and Horvath 1998; Fought 1999; Henderson 1995; Preston et al. 2009; Roeder 2010). Accordingly, this article argues for an ethnically-indexed variety of the Oklahoma English manifested in the acoustics of Persian-Oklahomans in comparison to the acoustics of European-Oklahomans as a reference group of similar age range and residence background.

\section{Language variation and change in a multilingual America}

During multiple studies in New York and Philadelphia, Labov (1966, 1969, 1972) established the quantitative paradigm in sociolinguistics which has ever since been instrumental in modeling language variation and change in monolingual and multilingual communities. The central idea of this approach is that the occurrence of alternative forms of linguistic elements - including but not limited to morphosyntactic, phonological, and lexical variation - in a given speech community is not random, but 
systematic. Sociolinguists have discovered that people have the choice to use two - or more - alternatives or linguistic variants in their linguistic performance, and that their choice may be influenced by a number of social and linguistic variables. Studies show that gender, age, socioeconomic level, and attitudinal factors and the extent to which individuals identify with their own social and ethnic groups can result in differences in the linguistic behavior of speech communities (e.g., Hoffman and Walker 2010). Wolfram (1974) even suggested an influence from a minority ethnic dialect variety onto the mainstream regional dialect when White Anglos had acquired copula absence from an African American ethnolect (Clyne 2000). Of course, in many American communities, ethnic categorization goes beyond black and white, and the same could be expected of the linguistic marking of these categories (Gordon 2000). Accordingly, one of the main assumptions of this systematic approach to interpreting dialect contact and linguistic variation is that synchronic variation is often a reflection of diachronic change (Weinreich et al. 1968).

Today, it is possible to observe and interpret language contact situations as they develop through adopting the theory of language variation and change (LVC) which explains language contact and linguistic change by the social context in which it occurs (Labov 1963). The goal of variationist sociolinguistics is to understand the mechanisms which link extra-linguistic phenomena with systematic and inherent variation in language through observation and interpretation (Tagliamonte 2011). In his studies on monolingual mainstream speakers of American dialects, Labov (2007) explains synchronic variation and diachronic linguistic change through transmission and diffusion. Phonetic transmission occurs when mainstream speakers of a dialect community acquire phonetic changes in small steps and so gradually that they might not be even aware of it. Vowel systems such as the Northern Cities Vowel Shift (NCS) and Southern Vowel Shift (SVS) are the outcome of such transmissions. Diffusion, on the other hand, has been mostly viewed in immigrant or bilingual communities where learners are influenced not only by the phonetic input of the dialect region, but also by the learners' previous phonological system(s).

\subsection{Studies on ethnic dialect varieties of American English}

Any understanding of the materialization of ethnic dialect varieties rests on models of language contact. A review of Weinreich's (1953) definition of interference will remind us that bilinguals' familiarity with more than one language is likely to result in their deviation from the norms of either language. Weinreich's idea is further narrowed in Thomason and Kaufman's (1988) interference situation when the L1 has the strongest effects on L2 phonology. The other side of Weinreich's notion of language contact is borrowing when L1 linguistic features are consistently affected by L2 features (Van Coetsem 1988). The bulk of the known influences of minority languages on American English dialects lies in phonetic and phonological interference (e.g., Lynn 1954; Penfield and Ornstein-Galicia 1985). Trudgill's (1986) model of new dialect formation describes situations where dialectally marked forms are discarded by speakers of dialect varieties (e.g., Dodsworth and Kohn 2012; Kerswill 1996; Lane 2000).

In a multilingual context, contact across language boundaries occurs when two or more languages are used at the same time and a majority/dominant language serves as the lingua franca connecting ethnic groups (Onysko 2016). Under such circumstances, migrants' speech hold a lower status which might lead to surfacing of certain linguistic features of their L1 in their L2 phonology as identity markers. A good example is the use of Cajun French markers in the English of young Louisiana Cajuns, indexing their ethnic identity through linguistic variables (Dubois and Horvath 2003) has been taken into account in examinations of the extent of linguistic transference in bilingual ethnic minority speech communities inside the US. Dodsworth (2008) demonstrates how vowel formant data can serve as indices of ethnic variation and language contact influence. In a multilingual America, immigrant speech communities rely on their heritage sources of linguistic features to select markers of their English varieties.

In a study on the vowel system of bilinguals residing in Lansing, Michigan, Preston et al. (2009) considered such contact in an immigration situation among Mexican-American speakers in Southern Michigan, in the Great Lakes area of the United States. Results indicate that, unlike mainstream speakers of large cities in Michigan who tend to use an asymmetric pattern in their vowel system, known as Northern Cities Shift, Mexican-American ESL learners and their descendants have developed a different system 
influenced by the symmetric vowel system of Spanish. Similarly, acoustic plots of the Lebanese community of Dearborn, Michigan, do not show an adaptation of the native Northern Cities Shift; rather, the phonetic system used by this ethnic minority is more compatible with Arabic norms (Bakos 2012). Many similar studies (e.g., Roeder 2006; Thomas 2018) show that ethnicity and cultural orientation are among the social phenomena which would influence linguistic variation when multitudes of people with different home languages settle in a region.

The present sociophonetic study was motivated as a result of the author's observation of variation in Persian identities assumed by second-generation Persian-Oklahomans. This study is part of a larger project which aims at modeling dialects in contact across boundaries of Tehrani Farsi and Oklahoma English in a context where Farsi-speaking immigrants and their descendants have moved to the state of Oklahoma. In other words, it aims to explain how members of the Persian ethnicity have dealt with their new linguistic context in Oklahoma.

\section{Oklahoma dialect}

While scholars no longer speak of Peterson and Barney's (1952) 'General American' English (e.g., Preston 2005), this vowel system, hereinafter $P \& B$, remains a valuable point of comparison for variationist and dialectological studies in the US. In the context of this study, use of P\&B will be made to outline the characteristics of the Oklahoma dialect as the variety second-generation Persian-Oklahomans would have most likely encountered on the streets.

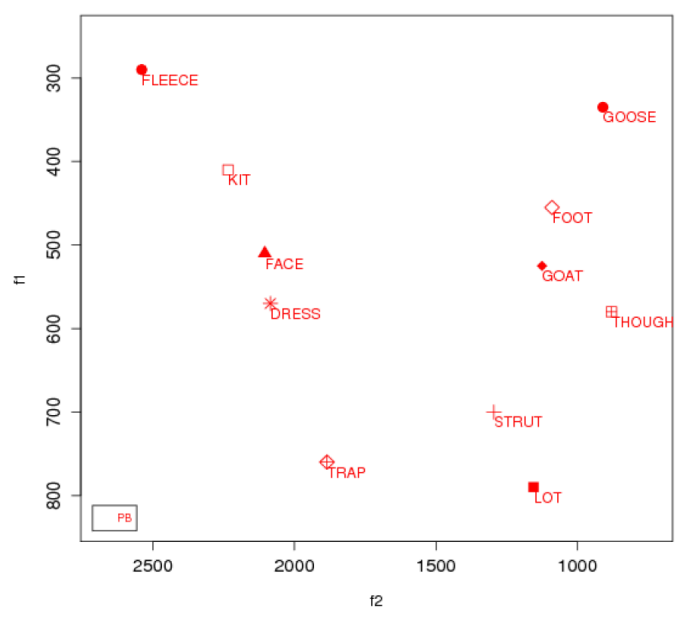

Figure 1. Averaged men and women's vowel mean from Peterson and Barney (P\&B) (1952)

A quick observation of the P\&B system will tell us that vowels are almost evenly spread out from one another, forming a fairly symmetrical vowel space. Unlike parts of the South where there is a lowering and retraction of the FACE and FLEECE classes (Thomas 2001), the P\&B vowel space holds the order of tense FLEECE above lax KIT, and tense FACE above lax DRESS. A Southern Shift influence would cause DRESS to raise, whereas a more northern configuration of mid-front vowels would have a descending order of FACE, DRESS and TRAP vowels.

The PIN/PEN merger is characterized by neutralizing influence of nasals $/ \mathrm{m} /$ and $/ \mathrm{n} /$ on preceding high and mid front lax vowels KIT and DRESS in traditional Southern speakers. This merger is a long-standing feature of European-American dialects in Southern states. Similar studies in Southern states suggest that the unmerging of these vowels before nasals is occurring (e.g., Tillery and Bailey 2008). According to Thomas (1997), non-southerners immigrated to the Southwestern US and moved into the suburbs of the largest metropolises as a result of the Sunbelt migration. He further claims establishment of markedly 
unmerged PIN/PEN vowels in the large cities of Texas as a result of Southern-born Sunbelt children's failure to assimilate to this traditional Southern merger. Similarly, Koops et al. (2008) suggests how young PIN/PEN speakers in Houston, Texas may be undoing their merger. Yet, unlike those regions, the unmerger is not as widespread in Oklahoma speech (e.g., Bakos 2013). Previous studies suggest that age and urban vs. rural location of residence are important factors associated with production of PIN/PEN vowel classes (e.g., Weirich 2013). However, despite these observed dialect movements in Southern states, PIN/PEN merger is still holding ground as a consistent feature of Oklahoma speakers in more recent studies (e.g., Bakos 2013).

Shifting our focus to the back of the P\&B vowel system, the GOOSE vowel will be spotted above lax FOOT. In contrast, fronting of the vowels in the GOOSE, FOOT, and GOAT classes is a salient feature of the Southern shift (Tillery and Bailey 2008). Observed in much of the Southern states, the THOUGHT/LOT merger was predicted by Baily et al. (1993) when they suggested a diffusion pattern of the merger from urban settlers to rural areas with their LOT vowel occupying the bottom corner of their vowel space. Finally, PRICE monophthongization or "glide weakening" (Thomas 2008), as a feature commonly associated with lower-class traditional speakers of Southern dialects, is attested in Southern speech when speakers of this dialect variety shorten the offglide before voiceless consonants in word-final position.

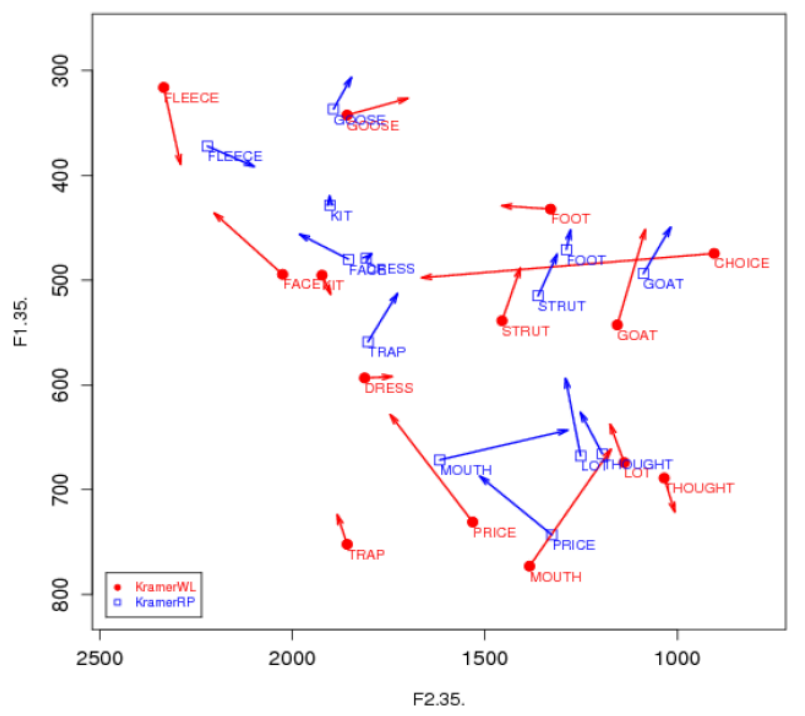

Figure 2. Kramer - male, 24, Broken Arrow - non-normalized from Bakos (2013)

Research from the Dialects of English in Oklahoma (RODEO) project has looked at the unique and rich diversity of Southern dialect features within Oklahoma State. Filling the gaps of older research on Oklahoma dialects, Bakos (2013) lends a point of reference for understanding the strong amount of variation within the state. In his (2013) study, Bakos chose not to present almost any findings in averaged aggregate and focused on individual speakers instead. Figure 2 displays the word list vs. reading passage vowel systems produced by Kramer, one of his younger respondents from suburbs of Tulsa. Bakos (2013) reveals that Oklahoma speech is not uniformly Southern even though he cites native Oklahomans who would claim so.

Similar to Thomas' (2001) findings, RODEO speakers illustrate a common pattern to front GOOSE, and a consistent raising and fronting of MOUTH. Unlike traditional Southern speakers, younger speakers tend to produce THOUGHT and LOT closer together in terms of F1 and F2 values. Similar to his claim, Weirich (2013) shows the Midland influence of THOUGHT/LOT merger and the prevalence of this feature in Oklahoma dialects. However, PIN/PEN merger is observed as a more consistent feature of Bakos's speakers than the THOUGHT/LOT merger. Thomas (2008) and Koops et al. (2008) have suggested that merging of KIT 
and DRESS before nasals is not confined to the South, yet younger speakers in the South may be working to undo it due to their perception of this merger as a stigmatized variety.

Continuing with the investigation of front vowel configurations in Oklahoma, previous studies report the complete absence of the inversion of FLEECE/KIT vowels and presence of the irregular or incomplete convergence of FACE/DRESS vowels in some speakers. In his findings, Bakos (2013) talks about Oklahoma speakers who had FACE/DRESS reversal, yet did not produce "the prerequisite for later stages of the Southern Shift," which is PRICE monophthongization (Labov et al. 2006; Thomas 2001). In Figure 2, Kramer displays parallel FACE / DRESS vowels in the reading passage (RP) task but maintains a distinction in his more careful reading of the wordlist (WL) task.

According to the mentioned literature on dialectology, mainstream Oklahoma vowel system displays a local mix of Southern and Midland features. However, variation in vowel formant values is expected depending on the age of speakers as well as their place of origin. This research aims to further explore Oklahoma vowel system through studying synchronic acoustic variation produced by an ethnic minority speech community in their wordlist, reading passage as well as spontaneous speech.

\section{Persian-Oklahomans}

Immigration of Persians to the United states dates back two centuries. Persian immigrants have been known as individuals who are adept at assimilating to American culture while holding on to their Persian roots (Emami 2014). Within the context of this research, immigrant Persian-Oklahomans are individuals who immigrated to Oklahoma from Iran over 25 years ago. Their children are referred to as second-generation Persian-Oklahomans. Through participating in their cultural events as well as interviewing members of this ethnic minority speech community, the author has observed that elements such as family, Farsi language, Persian New Year (Nowruz), Persian food, hospitality, courtesy and respect for elders are important to the members of Persian communities as the staples of Persian values. The Oklahoma community of PersianAmericans in this study was established by well-educated and highly accomplished immigrants who wish to ensure that future generations celebrate their Persian culture and heritage.

The immigrant Persians moved to Oklahoma as exchange students around the 1970s. They married, raised their families and opened businesses and built careers in Norman, Oklahoma and in and around Oklahoma City, Tulsa and Edmond. By population, Norman is the third-largest city in Oklahoma whose racial makeup is about 85 percent European-Americans. Many of these immigrant Persian-Oklahomans have been significant contributors to the founding of a number of local and national organizations that maintain, enrich, and celebrate Persian culture and presence. During sociolinguistic interviews, secondgeneration Persian-Oklahomans stated that they had been immersed in their heritage and had been able to maintain strong bonds with their Persian heritage and their parents' homeland. Their regular and sporadic cultural practices have taken many forms, from visiting Iran, taking Farsi language classes in college, establishing Persian music bands, conferences, workshops, film screenings and art exhibits. A marble statue of Omar Khayyam, the 11th century Persian polymath, stands outside the David L. Boren College of International Studies at Farzaneh Hall at the University of Oklahoma. This statue is one of the largest publicly visible Persian symbols which, as stated by one of the participants, "plays an important role in bolstering a sense of cultural pride among younger generations."

Despite the increasing presence of Persians in the U.S. and the shift to English among US-born generations, to the author's knowledge, this study is the first attempt to examine English spoken by USborn Persian-Americans through the lens of LVC. It is likely that this lack of previous research has occurred in part because members of Persian-American communities who speak English natively are considered to not have an ethnically distinctive variety of English. Rather, they are often seen as culturally and linguistically accommodating to middle-class European-American norms. Hypothesizing that the features of Farsi phonology may be carried over into the English variety used by second-generation PersianOklahomans, this study is intended to challenge these assumptions through an investigation of the English vowel systems of a representative group of second-generation Farsi-speaking Oklahomans. 


\section{$5 \quad$ Method}

\subsection{Participants}

As a representative cross-section of second-generation Persians-Oklahomans, twenty speakers - ten female, ten male - fulfilled several inclusion criteria. First, the participants' parents were both required to be Iranians who immigrated to the US over 25 five years ago. All the speakers were born and raised in Oklahoma, and were self-reported native speakers of English; however, in their sociolinguistic interviews, most of them claimed that they began speaking English at the start of primary school and they considered Farsi as their first and home language.

For a reference European-Oklahoman vowel system, recordings of reading passage (RP) and wordlist (WL) read by ten young, urban European-Oklahoman speakers - five female, five male - were selected from the RODEO archive. Both speaker groups were ages 18-30 and born and raised in urban parts of Oklahoma.

\subsection{Data collection and vowel measurements}

The collection of natural data is crucial in the Labovian quantitative paradigm. Labov claims that the more aware the participants are that their speech is being studied, the less natural their performances will be (Labov 1972). In other words, the more casual speech is, the more systematic, and thus more revealing of a speaker's basic language system, or vernacular (Preston 1996). Sociolinguistic interviews typically include a range of performance tasks ordered from the most casual to the most formal style. Accordingly, three stylistically different tasks were used to elicit English vowels from second-generation Persian participants' speech, beginning with an informal interview. Through previous observation of the PersianOklahoman speech community and their cultural practices, socially acceptable topics were discussed on their cultural practice and living experience as Persian-Americans. The goal of the interviews was to approximate natural conversations. All interviews were conducted entirely in English.

Next, participants read a short passage (Appendix A), and finally a wordlist (Appendix B). The wordlist (WL) and reading passage (RP) were developed and used in previous studies in the RODEO project in order to account for a consistent set of tokens across all the speakers. Digital recordings were made at 44,000 Hz using a Marantz portable recorder. Machine generated transcripts were checked and edited manually and then transferred to text grids using a Praat script. DARLA Semi-automated suite was used to force align (McAulliffe et al. 2017) and extract (Rosenfelder et al. 2014) F1 and F2 vowel measurements using the DARLA web interface (Reddy \& Stanford 2015) and the Vowels R package (Kendall and Thomas 2010).

Coarticulatory effects of liquids, glides and nasals on vowel measurements were controlled through filtering out tokens where these segments would precede and/or follow the target vowels. This resulted in 1842 usable tokens produced by Persian-Oklahomans in their WL/RP speech with three to ten tokens of each vowel class per person. The Persian-Oklahoman tokens were then compared to three to seven usable tokens for each of the vowel classes produced by European-Oklahomans. Finally, second-generation Persian-Oklahoman interview data were analyzed for formant values of $/ \mathrm{I} / \mathrm{and} / \varepsilon /$ in 1640 tokens.

Finally, first and second formant measurements were plotted with averages for the nuclei taken at $35 \%$ of vowel duration and the glide at $80 \%$ of vowel duration to minimize target vowels' interaction with onset and coda consonants as much as possible. To prepare the data for analysis and for comparison between groups, Persian-Oklahoman (PR-OK) and European-Oklahoman (EU-OK) speakers' vowels were Labov ANAE-normalized together using the Telsur G value in NORM v.1.1 (Thomas and Kendall 2007) in order to account for differences in vocal tract configurations. The resulting plots include mean nucleus and glide measurements per vowel class. Pre-nasal allophones of the KIT and DRESS class were plotted as separate PIN/PEN vowel classes. Then, the individual plots for each Persian-Oklahoman speaker were inspected separately in order to identify any potential outliers. 
Traditional demographic information as well as information about Persian-Oklahoman speakers' social network strength and Persian cultural practices were collected through estimating their self-reported percentage of time they associate with Persian immigrants, second-generation Persian-Oklahomans, and European-Oklahomans (Appendix C). In addition to their social network score, a separate set of questions was designed to measure their cultural practice score. Second-generation Persians' self-reported percentage of participation in Persian-themed gatherings, and festivals and their interest in Persian music, movies, and books were the elements that would contribute to their assigned cultural practice score (Appendix D).

\section{Results}

\subsection{Interaction between Farsi and Oklahoma vowel systems}

Studies such as Yeni-Komshian, Flege, and Liu (2000) suggest that an L1 offers an initial skeleton upon which an L2 can be built. Bilinguals strive to maintain contrast between L1 and L2 phonetic categories (Eckman 2004). Any attempt to understand contact across languages rests on the comparison of the L1 and L2 systems, and a predication of the learner/contact outcome (Preston et al. 2009). For PersianOklahomans, the earliest and most convenient source is Farsi as their native language. In a separate study on Persian immigrants' linguistic and social experiences with the Farsi variety spoken by second-generation Persian-Oklahomans (Dokhtzeynal and Sheikhbahaie 2020), one of the most salient folk linguistic comments was parents' sense of pride in setting Farsi as their home language with no to very little exposure to English. Studies on phonological representation and speech production reveal that early native language commitment contributes to early bilinguals' abilities to perceive and produce sound contrasts of an L2 phonology (Pallier et al. 1997; Sebastián-Gallés and Soto-Faraco 1999). Therefore, since the concern of this paper is pronunciation, a comparison of the Farsi vowel system and a typical Oklahoma vowel system is required.

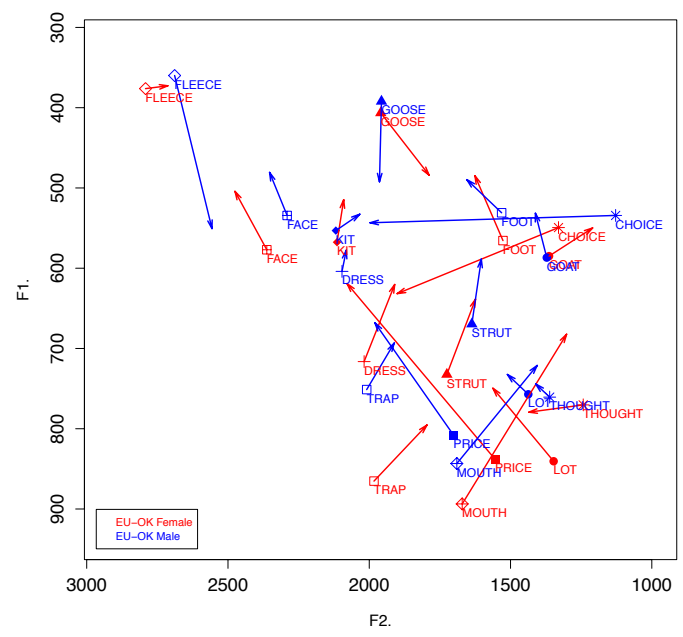

Figure 3. European-Oklahoman vowel spaces - normalized

Figure 3 displays normalized male and female vowel spaces produced by ten European-Oklahomans. Speakers' vowel plots were drawn based on vowel tokens measured from their readings of RODEO RP and WL tasks. A quick inspection of the plots reveals a similar pattern between male and female Oklahomans. We can see GOOSE fronting and a shift in FOOT in both groups. In general, young urban speakers maintain their FACE vowel higher than DRESS although, with these speakers, males' DRESS is fairly close to FACE, 
which could reflect a remnant of FACE/DRESS convergence. European-Oklahoman females look more Midwestern, particularly with their lower DRESS and TRAP vowels.

In an acoustic description of Farsi vowels produced by native speakers of the Tehrani dialect, Ghaffarvand Mokari et al. (2017) explored the Farsi inventory of six vowel phonemes /i/, /e/, /p/, /æ/, /o/ and $/ \mathrm{u} /$. Figure 4 overlays the mean values for an aggregated European-Oklahoman vowel system and the Tehrani Farsi vowel system to characterize the phonetic systems involved and make predictions about the developmental pathways of learners and bilingual speakers of these two linguistic systems.

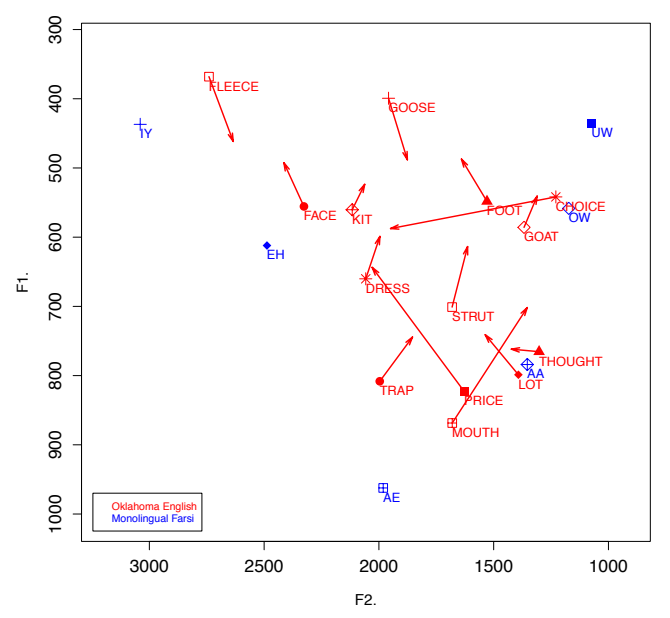

Figure 4. European-Oklahomans' English vowels (both sexes combined from Figure 3; red) and the Farsi vowels (of 25 monolingual Tehrani speakers from Ghaffarvand Mokari et al. 2017; blue ) - normalized

Figure 4 illustrates the acoustic difference between Tehrani Farsi and the most probable vowel system encountered by second-generation Persian-Oklahomans after they were introduced to the Oklahoma dialect through education system, integrating with their peers, and forming a rich social network of friends. Following Ghaffarvand Mokari et al. (2017), the monolingual Farsi vowel plot is limited to steady state vowel nuclei and does not include glides. This limitation is perhaps rooted in the disputed status of Farsi diphthongs with some scholars claiming them to be combinations of vowels with $/ \mathrm{j} /$ and $/ \mathrm{w} /$ (e.g., Windfuhr 2011; Alamolhoda 2000).

The size and phonetic quality of Farsi and English vowel inventories are different. Farsi has a smaller inventory of vowel phonemes without the tense-lax difference (Samare 1985; Yarmohammadi 1985). In contrast, the Oklahoma vowel system has a different configuration where $/ \mathrm{u} /$ is fronted and /æ/ appears higher, compared to Farsi. A closer look at Figure 4 can lead to the prediction that, assuming a substrate influence, Persian-Oklahoma English should display a vowel space with a backed GOOSE vowel and a lowered TRAP vowel. Provided that the substrate effect hypothesis turns out to be true and secondgeneration Persians fail to maintain a strong tense/lax contrast in their front vowels, we might expect their English KIT vowel to be closer to FLEECE with no display of the parallel KIT/FACE configuration which was observed in the speech of European-Oklahomans. Interestingly, the Farsi low back vowel / $\mathrm{p} /$ occupies the same area as the THOUGHT/LOT merger, which makes it reasonable to predict the same merger in the speech of Persian-Oklahomans.

The twenty Oklahoma-born participants discussed in this study were identified as fair-to-good speakers of heritage Farsi who claimed Farsi as their first and home language and Persian as their dominant cultural orientation, yet they also maintained a rich social network with middle-class European-Oklahoman speakers of the Oklahoma dialect. Figure 5 presents a revealing pattern of their acoustic participation in the linguistic context in Oklahoma in an overlay of their vowel space on the reference European-Oklahoman vowel system previously displayed in Figure 4. 


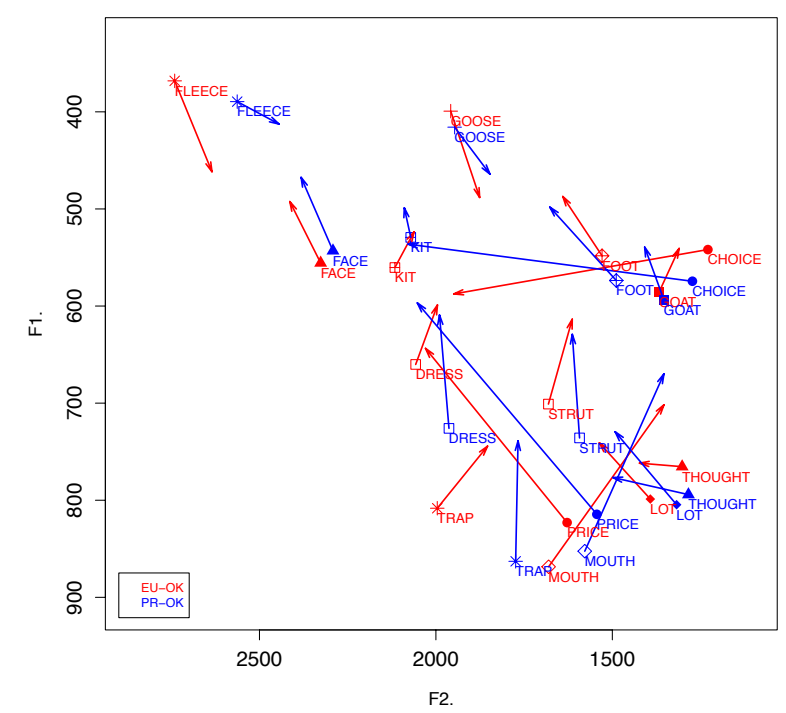

Figure 5. European-Oklahomans’ English vowels (red) and Persian-Oklahomans’ English vowels (blue) normalized

Persians and Europeans displayed nearly identical vowel values except in Persians' lowered DRESS vowel and their noticeably lowered/backed TRAP vowel class.

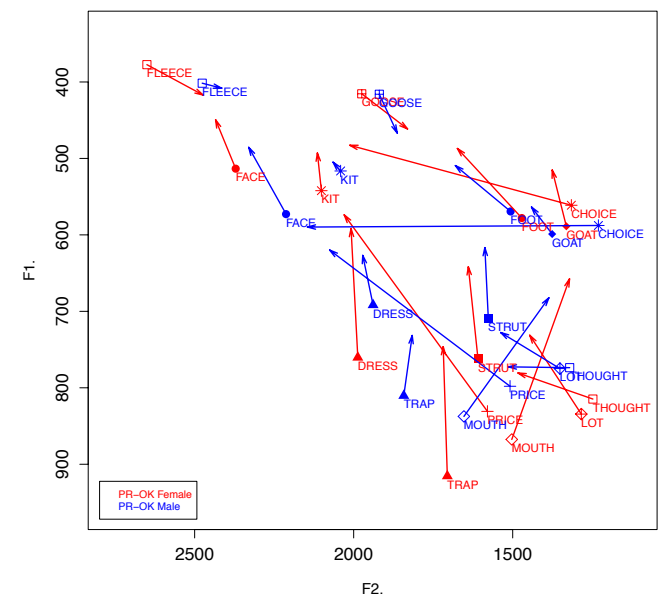

Figure 6. Second-generation Persian-Oklahoman vowel spaces - normalized

Figure 6 separately plots normalized values for male and female second-generation English vowel systems. Accordingly, male and female configurations are similar except for a lowered and slightly backed TRAP vowel in female speech. On the other hand, female speakers maintain the KIT/FACE inversion while male speakers show a more Midwestern tense/lax configuration in their front vowels.

\section{$7 \quad$ PIN PEN merger}

This section zooms in on pre-nasal allophones of KIT and DRESS vowels in the speech of second-generation Persian-Oklahomans to investigate their production of PIN/PEN merger. In order to understand the typical merger that is available to Persian hearers and speakers of the Oklahoma dialect, 64 usable tokens of PIN/PEN vowels and 88 tokens of KIT/DRESS were extracted from the WL and RP data for European- 
Oklahoman speakers. The aggregate mean scores for their production of these vowel classes are displayed in Figure 7.

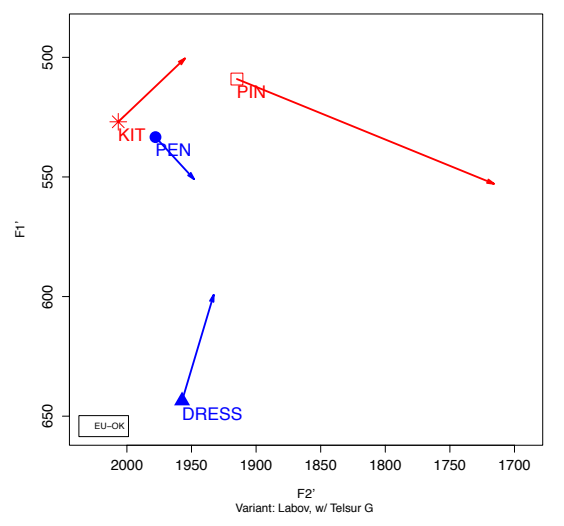

Figure 7. European-Oklahoman /I/ and / $/$ / vowels - normalized

The presence of PIN/PEN merger in the speech of these ten European-Oklahomans in Figure 7 is consistent with previous studies on Oklahoma speakers. This representative vowel plot makes it very likely that second-generation Persian-Oklahomans have encountered the merger among their peers and are likely to adopt this merger just like they did with other Oklahoma dialect features previously discussed. Table 1 shows the number of usable tokens produced by second-generation Persian-Oklahomans for $/ \mathrm{I} /$ and $/ \varepsilon /$ vowels in their RP and WL. Figure 8 illustrates the results of our probe for a potential PIN/PEN merger by these speakers.

Table 1. Persian-Oklahoman Usable Tokens for $/ \mathrm{I} /$ and $/ \varepsilon /$ Vowels

\begin{tabular}{lll}
\hline vowel class & female & male \\
\hline PIN & 30 & 46 \\
PEN & 33 & 58 \\
KIT & 59 & 80 \\
DRESS & 40 & 61 \\
\hline
\end{tabular}
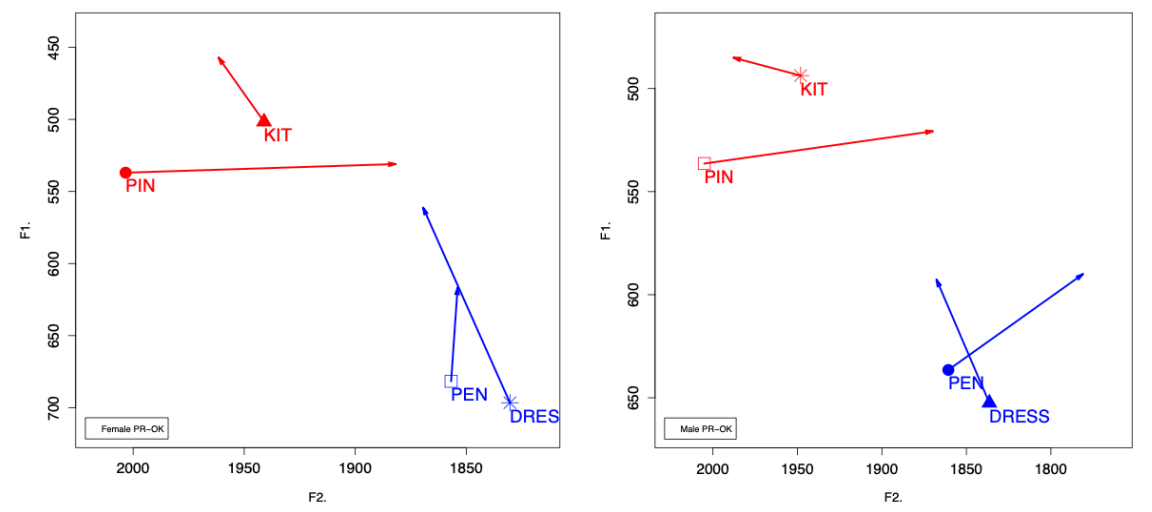

Figure 8. Persian-Oklahoman $/ \mathrm{I} /$ and $/ \varepsilon /$ vowels (female, left; male, right) - normalized 
Unlike the European-Oklahomans in Figure 7, Persian speakers of Oklahoma English produce strongly split - unmerged - PIN/PEN vowels. Based on Figure 8, sex does not appear to be a deciding factor in their pre-nasal production of $/ \mathrm{I} /$ and $/ \varepsilon /$ vowels. Further evidence is provided in Figure 9 which separately plots their differentiation of PIN/PEN vowel classes across the two speech tasks.

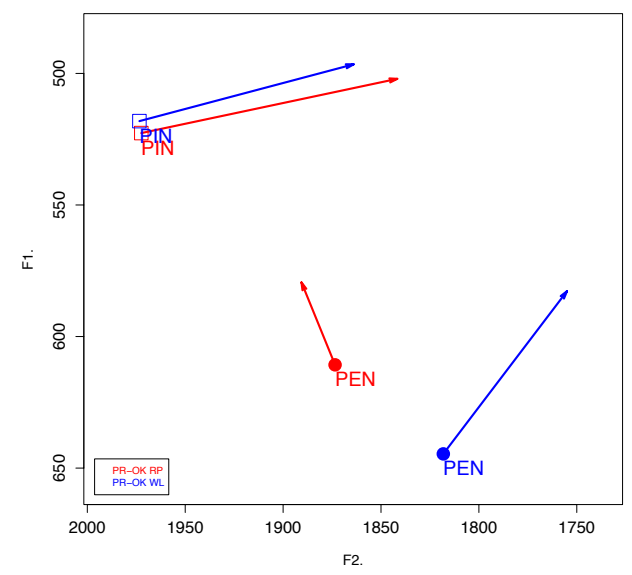

Figure 9. Persian-Oklahoman PIN/PEN vowels across RP/WL speech styles - normalized

In Figure 9, we can clearly notice the effect of RP context on Persians' slightly closer production of PIN/PEN vowels, but their production remains within an acceptable range of split with a roughly $100 \mathrm{~Hz}$ difference in their RP F1 values. This observation of their slightly raised PEN vowel calls for an investigation of the sociolinguistic interview data collected from these speakers. These sociolinguistic interviews are a source of their casual conversations and storytelling. It is assumed here that their more casual speech is more systematic, and thus more revealing of Persian speakers' phonological representations, or vernacular. Figure 10 shows the configuration of male and female second-generation Persians' $/ \mathrm{I} /$ and $/ \varepsilon /$ vowels across the continuum of speech styles:
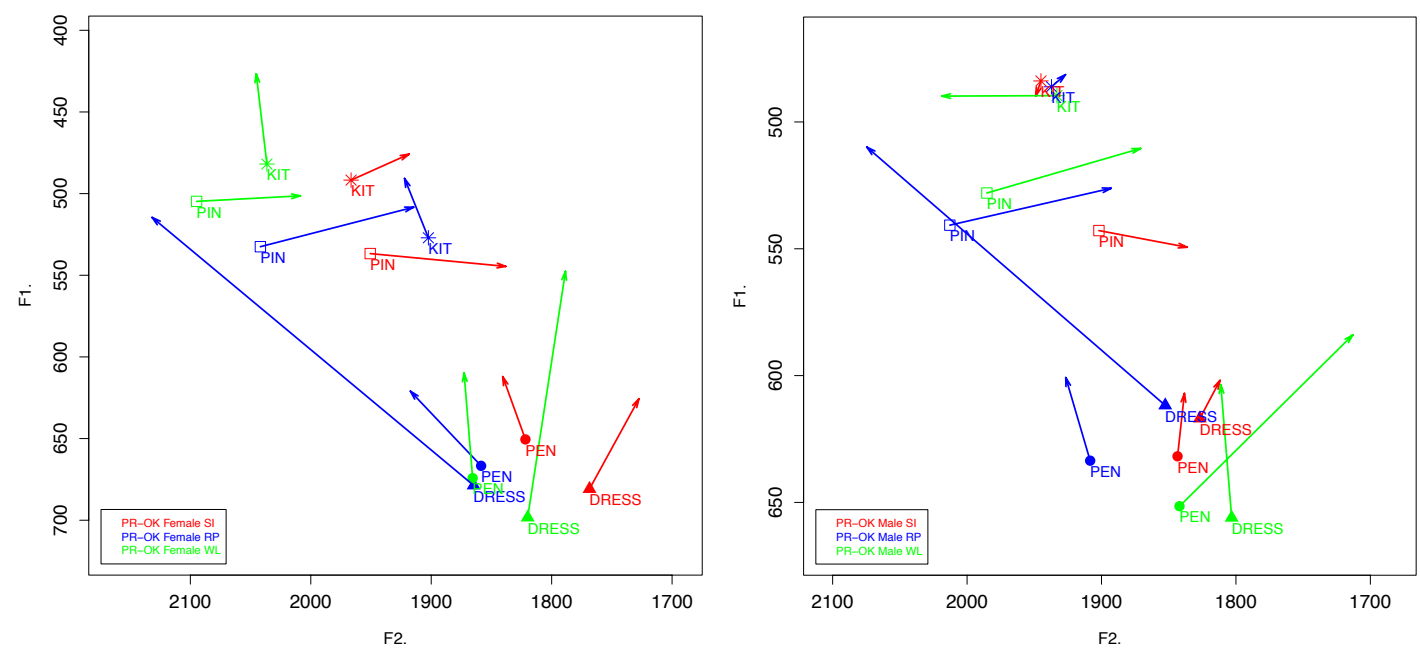

Figure 10. Persian-Oklahoman /I/ and /E/ vowels (female, left; male, right) - normalized

A quick comparison of the two plots across male and female speakers in Figure 10 reveals the same consistent split pattern in PIN/PEN vowel configurations regardless of the speech task. It is to note that the 
red plots are based on aggregated values of $872 / \mathrm{I} /$ and $/ \varepsilon /$ tokens from interviews with female Persians and 768 tokens from interviews with male speakers.

\section{Discussion}

This study set out the goal to describe second-generation Persian-Oklahomans as an ethnically-specified speech community in Oklahoma and to compare their production of vowels to the mainstream dialect community. Acoustics of European-Oklahoman speakers revealed a similar pattern between male and female speakers, yet unlike male speakers, young female European-Oklahomans displayed a descending order of DRESS and TRAP vowels and produced a more northern configuration of their mid-front vowels (Figure 3). Similarly, Figure 6 displayed a lowered configuration of these vowels in the speech of Persians with an additional backed TRAP vowel class. This variation in their F2 formant value was more noticeable in Figure 5 and could be interpreted as their indexing their California-oriented Persian identity. It is hard to believe that linguistic interference from their heritage Farsi language is resulting in their backed TRAP vowels because, as we learned from the overlay of monolingual Farsi and Oklahoma English vowels in Figure 4, Farsi /æ/ vowels and English TRAP share a similar F2 value. Persian-Oklahomans' noticeable lowering and backing of TRAP vowel raises the possibility of their being influenced by input from nonSouthern dialects in California. One of the most recurring themes in their sociolinguistic interviews was their frequent contact with their Persian-American relatives and cousins in California and their identification with them as the largest Persian enclave in the US. This existing discoursal evidence could support their exposure to the kind of acoustic input that would make them sound more Californian and less Oklahoman. However, it is essential to gather more discoursal and acoustic evidence before we can make such a speculation.

Among other similar California-oriented themes, second-generation Persian-Oklahomans shared their intentions of moving out of the state and joining Farsi-speaking communities in California. They narrated stories of their parents' affluent urban lifestyle and their mainly educational purposes for moving to the US. They also mentioned the unstable economy at the time of the Iranian revolution as the main cause of their parents' preference to make their life in a small Oklahoma college town instead of relocating to metropolitan areas after graduation.

On the other hand, their Persian upbringing makes these second-generation Persians want to stay close to their parents even beyond college age and after marriage. Even though they express feelings of satisfaction with being American, their comments indicate their adoption of a stronger Persian identity which partly explains their obsession with moving to California and getting to experience a Persian lifestyle without "being judged for their looks and their cultural practice." This is especially true with young Persian women whose hobbies and ideologies resemble a stereotypical Persian girl who is constantly monitored and accompanied by parents even during adulthood, forbidden to have sleepovers as a child or join sororities as an adult. This high level of supervision could explain Persian girls' tight social network with other Oklahoma-born Persians. On the other hand, male Persian-Oklahomans indicated greater networking with European-Oklahomans and other ethnic minority speech communities. Yet, their participation in Persian cultural practice is no less than female speakers because "that is what makes Persian parents happy," and "motivates them to pay for expensive trips to Iran."

Given these demographic traits and cultural orientations, we could expect to notice more indices of ethnic variation in their Persian-Oklahoma English. An investigation of their pre-nasal KIT and DRESS vowels provided solid evidence for the existence of a Persian identity marker in the speech of PersianOklahomans. Studies on the acoustics of Oklahoma dialect consistently report on production of PIN/PEN merger, a long-standing feature of European-American dialects in the South, as a feature that is still holding ground in Oklahoma (e.g., Bakos 2013; Weirich 2013). When Bakos (2013) asked Kramer (Figure 2) about the PIN/PEN merger, he made the comment 'I do it, so Oklahomans must do it.' However, it might be safe to assume that European-Oklahomans have developed a stigmatized regard for this phonological merger. Their awareness of the stigmatized variants is signaled in their merged production of PIN/PEN vowels in a less careful production of the RODEO reading passage while maintaining the split in their wordlist 
productions (e.g., Bakos 2013). On the other hand, Persian-Oklahomans' production of pre-nasal KIT/DRESS vowels prefer the split regardless of the speech style (Figure 10). This situation is analogous to the establishment of unmerged PIN/PEN vowels in the large cities of Texas when Southern-born children of Sunbelt migrants failed to assimilate to this traditional Southern merger. In a similar fashion, children of Persian immigrants are displaying markedly split PIN/PEN vowels despite their residence in comparatively smaller urban areas than those of Texas.

As discussed earlier, second-generation Persians' divergence from the acoustics of pre-nasal KIT/DRESS vowels in Oklahoma could be explained by drawing on their social as well as linguistic experiences in this dialect region. From some of the previously discussed themes about their demographic traits and cultural orientations, it is safe to assume that this young group of Persian-Oklahomans has experienced a different Oklahoma lifestyle than that of the reference European-Oklahoman group. Their frequent participation in Persian cultural practices and their intentions of promoting their Persian culture through holding events and volunteering in Persian-themed ceremonies is adding a different dimension to their American identity. This unique ethnic and social experience supports the claim that, in addition to Farsi, Persian-Oklahomans have been exposed to at least two English varieties in their lifetime: the Oklahoma dialect, through the education system and integration with their peers, and Persian-accented English, through parents and association with other Persian immigrants.

Results from Figure 4 predict a challenging perception and production experience for Farsi-speaking learners of English especially with the tense/lax contrast in English. The results of sociolinguistic interviews with a dozen Persian immigrants revealed their strong urge for raising second-generation PersianOklahomans as bilinguals (Dokhtzeynal and Sheikhbahaie 2020). Similarly, a general theme shared by second-generation Persian-Oklahomans presented their challenging school experience because they would have to start learning English through the education system. Their comments indicated a language contact situation between second-generation speakers' Farsi phonology and their L2 Oklahoma English. This contact across the two languages is similar to the English learning experience for the immigrant generation. However, there is no doubt that their L2 learning experience is far less challenging than that of their immigrant parents.

\subsection{Persian-Oklahoman immigrants}

Persian immigrants moved to Oklahoma in their college years and learned English mainly through associating with European-Oklahomans and partly through attending short-term ESL programs. Drawing on the construct of apparent time (Bailey et al. 1991), results of a larger study on the acoustics of immigrant Persian-Oklahomans may help in explaining the observed PIN/PEN split in the speech of second-generation Persian-Oklahomans. A comparison of these two groups' adoption of acoustic norms in Oklahoma could be revealing as to whether Persian-Oklahomans' divergence form the local PIN/PEN merger is constrained by their Farsi phonology or whether it stems from their exposure to the PIN/PEN split as a result of their frequent identification with Persian-Californians and their frequent participation in their social network. This discussion considers the acoustics by five male immigrants in its modeling of the developmental pathways of contact across Farsi and Oklahoma English.

Acoustic studies of the Oklahoma dialect indicate an unwavering presence of PIN/PEN merger in the speech of older generations of European-Oklahomans (Bakos 2013). Similar to their children, immigrant Persians have assumed a dual lifestyle with their roots in their Persian heritage and their ties with EuropeanOklahomans. A quick look at the speech of five male immigrant Persians illustrates a similar contact situation between Farsi and Oklahoma English. It is expected that the linguistic and social similarities between the immigrant generation and second-generation Persians will make them produce similar acoustic patterning. However, contrary to the observed split in PIN/PEN vowels by second-generation speakers, immigrant Persians should be expected to produce the PIN/PEN merger because they tend to associate with older European-Oklahomans whose pre-nasal KIT/DRESS vowels are most likely merged. Eager to blend in with their new community of friends, these five male Persian immigrants mentioned how they "purposefully maintained a distance with other Persian immigrants" in order to learn English from "Americans" in 
Oklahoma and be able to establish their business during their early years of immigration. In traditional views of Persian society, men would assume the role of the sole provider. It is assumed that this traditional expectation has provided male immigrants with more access to the Oklahoma English vernacular.

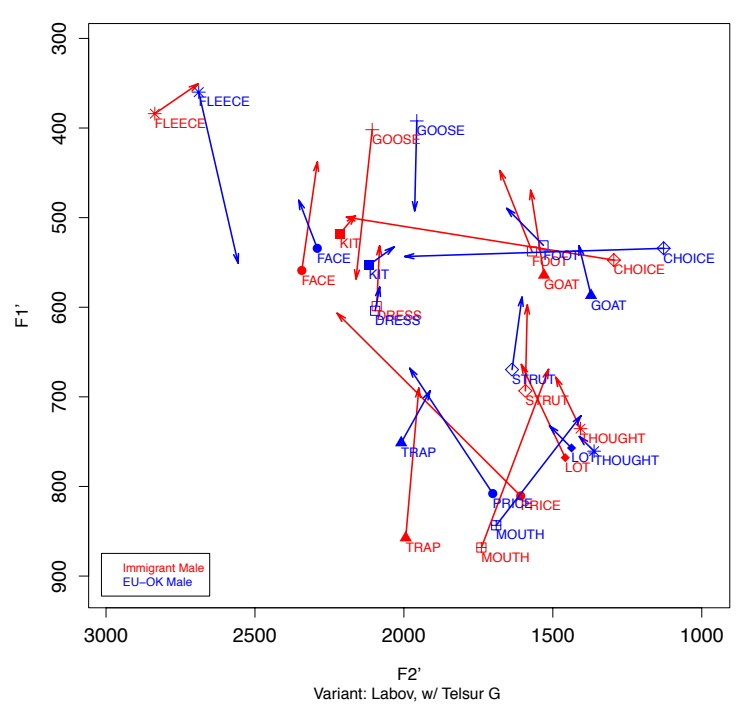

Figure 11. Male Persian-Oklahoman immigrants' English vowels (red) and male European-Oklahomans' English vowels (blue) - normalized

An overlay of the English variety used by immigrant Persians on Oklahoma English displays how native-like their acoustic production has grown to be over the last twenty-five years. Despite their smaller inventory of L1 vowel phonemes (Figure 4), they are able to maintain the tense/lax contrast in their L2 phonology. Not only do they manage to produce tense GOOSE and distinguish it from the lax FOOT vowel, they also front their GOOSE vowel just like native Oklahomans do. These five older Persian-Oklahomans immigrated to Oklahoma in their early twenties. This older age of L2 phonology acquisition could explain their slightly larger English vowel space as well as their lowered TRAP in their Oklahoma English, influenced by formant values in their Farsi /æ/ analyzed by Sheikhbahaie (to appear 2020). Considering their self-reported exposure to the Oklahoma dialect for over 25 years, the immigrant generation's Oklahoma-like acoustic targets invite us to expect PIN/PEN merger in their production data.

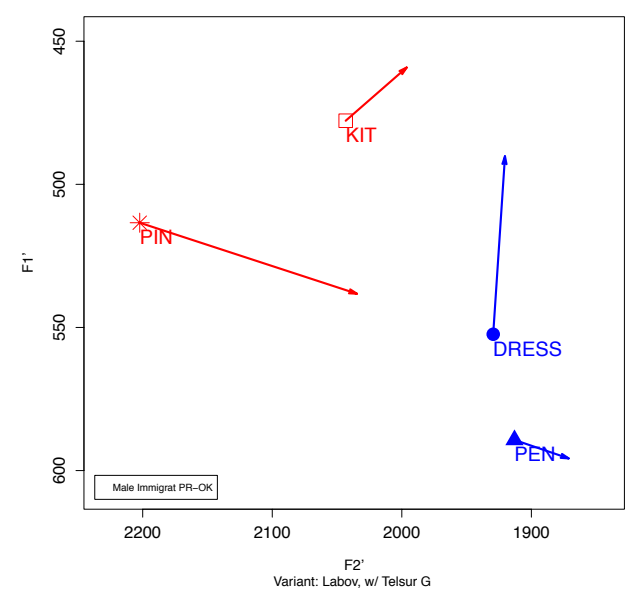

Figure 11. Male Persian-Oklahoman immigrants'/I/ and /E/ vowels - normalized 
Acoustic measurements of immigrants' KIT/DRESS vowel tokens in pre-nasal environments remind us of Figure 8 where a similar PIN/PEN split was demonstrated in the speech of second-generation Persians.

This overview of the acoustics of the immigrant generation revealed the accented-English variety to which second-generation Persians have been exposed. At this point in our discussion, it is reasonable to claim that second-generation Persians' exposure to this accented variety has established an ethnic variety of Oklahoma English characterized by PIN/PEN split to index their Persian identity. Another explanation for the PIN/PEN distinction shared in the English of both generations is linked to their frequent association with Persian-Californians. It is to note that PIN/PEN merger is hardly a feature of West Coast English. Additionally, second-generation speakers' cultural orientations and unique upbringing might have affected their living experience in Oklahoma and made them lean toward their Persian identity which is manifested in their PIN/PEN vowel classes.

\section{Conclusion and Future Directions}

The main conclusion drawn from the present study is that the contact across the language boundaries of Farsi and Oklahoma English reveals both assimilation and resistance to assimilation to the local speech norms despite Persian-Oklahomans' contact with the dominant European-Oklahoman ethnic group. This paper proposed a relationship between the existing synchronic variation in the acoustics of PersianOklahomans and the influence of their heritage Farsi, Persian-American social network, and cultural orientations on their production of pre-nasal DRESS and KIT vowels. Second-generation speakers' lowering and backing of the TRAP vowel was postulated as another index of Persian identity influenced by their constant identification with their Persian enclave in California.

To the author's knowledge, this study was the first attempt to examine distributional trends of the English vowels produced by Persian-Americans through the lens of LVC. The next step would be to examine how Persian-Oklahomans' perception of the PIN/PEN merger and frequency of exposure to this dialect feature would affect their production targets in English. One hypothesis would suggest secondgeneration Persian-Oklahomans' dialect leveling in their speech community due to their affiliation to the "standard" California variety and their constant exposure to the Farsi-accented English variety used by their parents. Similar acoustic investigations on other ethnic minority speech communities will contribute to a better understanding within sociolinguistics of the construction of linguistic identity in a multilingual America.

Acknowledgements. I would like to thank my thesis supervisor Dennis Preston and sociophonetician Valerie Freeman for their insightful comments on earlier versions of the manuscript.

\section{References}

Alamolhoda, Seyyed Morteza. 2000. Phonostatistics and Phonotactics of the Syllable in Modern Persian. Studia Orientalia 89.

Bailey, Guy, Tom Wikle, Jan Tillery, and Lori Sand. 1991. The apparent time construct. Language Variation and Change 3(3): 241-264.

Bailey, Guy, Tom Wikle, Jan Tillery, and Lori Sand. 1993. Some patterns of linguistic diffusion. Language Variation and Change 5(3): 359-390.

Bakos, Jon. 2012. Investigating the Northern cities shift in the Lebanese community of Dearborn, Michigan. Master's thesis, Michigan State University

Bakos, Jon. 2012. Investigating the Northern Cities Shift in the Lebanese community of Dearborn, Michigan. Lingua y migración/Language and Migration 4(1): 5-31.

Bakos, Jon. 2013. A Comparison of the Speech Patterns and Dialect Attitudes of Oklahoma. Doctoral dissertation, Oklahoma State University. 
Bayley, Robert James. 1991. Variation theory and second language learning: Linguistics and social constraints on interlanguage tense marking. Doctoral dissertation, Stanford University.

Bayley, Robert James. 2002. The quantitative paradigm. The handbook of language variation and change, ed. Jack Chambers, Peter Trudgill, and Natalie Schilling-Estes, 117-41. Oxford: Blackwell

Bayley, Robert James. 2017. Presidential Address: Dialectology in a Multilingual America. American Speech, 92(1): 6-22. doi:10.1215/00031283-4153175

Clopper, Cynthia G. 2014. Sound change in the individual: Effects of exposure on cross-dialect speech processing. Laboratory Phonology 5(1): 69-90. http://dx.doi.org/10.1515/lp-2014-0004

Clyne, Michael. 2000. Lingua franca and ethnolects in Europe and beyond. Sociolinguistica 14(1): 83-89.

Dodsworth, Robin. 2008. Sociological consciousness as a component of linguistic variation 1. Journal of Sociolinguistics 12(1): 34-57.

Dodsworth, Robin, and Mary Kohn. 2012. Urban rejection of the vernacular: The SVS undone. Language Variation and Change 24: 221-45.

Dokhtzeynal, Shima, and Masoud Sheikhbahaie. 2020. Whaddatheyknow?: Persian Immigrant Parents' Awareness of Heritage Farsi. Paper presentation at the 2020 Georgetown University Round Table, Washington, DC.

Dubois, Sylvie, and Barbara M. Horvath. 1998. From Accent to Marker in Cajun English: A Study of Dialect Formation in Progress. English World-Wide, 19: 161-88.

Dubois, Sylvie, and Barbara M. Horvath. 2003. Creoles and Cajuns: A portrait in black and white. American Speech 78(2): 192-207.

Eckman, Fred R. 2004. From phonemic differences to constraint rankings: Research on second language phonology. Studies in Second Language Acquisition 26(4): 513-549.

Emami, Jessica. 2014. Iranian Americans: Immigration and assimilation. Washington, DC: Public Affairs Alliance of Iranian Americans.

Fought, Carmen. 1999. A majority sound change in a minority community: /u/-fronting in Chicano English. Journal of Sociolinguistics 3: 5-23.

Gordon, Matthew J. 2000. Phonological correlates of ethnic identity: Evidence of divergence? American Speech 75(2): 115-136.

Henderson, Anita. 1995. The Short 'a' Pattern of Philadelphia among African-American speakers. In (N)WAVES and MEANS: A Selection of Papers from NWAVE 24, ed. Miriam Meyerhoff. University of Pennsylvania Working Papers in Linguistics, 3(1): 127-40.

Hoffman, Michol F., and James A. Walker. 2010. Ethnolects and the city: Ethnic orientation and linguistic variation in Toronto English. Language Variation and Change 22: 37-67.

Kendall, Tyler, and Erik R. Thomas. 2010. Vowels: vowel manipulation, normalization, and plotting in R. R package. cran.r-project.org/web/packages/vowels/index.html.

Kerswill, Paul. 1996. Children, adolescents and language change. Language Variation and Change 8: 177202.

Labov, William. 1963. The social motivation of a sound change. Word 19(3): 273-309.

Labov, William. 1969. The social stratification of English in New York City. Washington DC: Centre for Applied Linguistics.

Labov, William. 1969. Contraction, deletion, and inherent variability of the English copula. Language 45: $715-762$.

Labov, William. 1972. Sociolinguistic patterns. Philadelphia: University of Pennsylvania Press.

Labov, William. 2007. Transmission and diffusion. Language 83(2): 344-387.

Labov, William, Sharon Ash, and Charles Boberg. 2006. The atlas of North American English: Phonetics, phonology, and sound change. Berlin: Mouton/de Gruyter.

Lane, Lisa Ann. 2000. Trajectories of linguistic variation: Emergence of a dialect. Language Variation and Change 12: 267-94.

Lynn, Klonda. 1945. Bilingualism in the Southwest. The Quarterly Journal of Speech 31: 175-80. 
McAuliffe, Michael, Michaela Socolof, Sarah Mihuc, Michael Wagner, and Morgan Sonderegger. 2017. Montreal Forced Aligner: trainable text-speech alignment using Kaldi. In Proceedings of the 18th Conference of the International Speech Communication Association.

Mokari, Payam Ghaffarvand, Stefan Werner, and Ali Talebi. 2017. An acoustic description of Farsi vowels produced by native speakers of Tehrani dialect. The Phonetican Journal of the International Society of Phonetic Sciences 114: 6-23

Onysko, Alexander. 2016. Modeling world Englishes from the perspective of language contact. World Englishes 35: 196-220.

Pallier, Christophe, Laura Bosch, and Núria Sebastián-Gallés. 1997. A limit on behavioral plasticity in speech perception. Cognition 64: B9-B17.

Penfield, Joyce, and Jacob L. Ornstein-Galicia. 1985. Chicano English: An ethnic contact dialect. Amsterdam: John Benjamins.

Preston, Dennis R. 1996. Variationist perspectives on second language acquisition. In Second language acquisition and linguistic variation, ed. R. Bayley and D. R. Preston, 1-45. Amesterdam: John Benjamins.

Preston, Dennis R. 2005. How can you learn a language that isn't there? In English pronunciation models: A changing scene, ed. K. Dziubalska-Kolaczyk and J. Przedlacka, 37-58. Bern, Switzerland: Peter Lang.

Preston, Dennis R. 2009. L1 and L2 dialects: Where the action is. Lengua y Migracion/Language and Migration 1(2): 5-20.

Reddy, Sravana, and James Stanford. 2015. A Web Application for Automated Dialect Analysis. In Proceedings of NAACL-HLT 2015.

Roeder, Rebecca V. 2006. Ethnicity and sound change: Mexican American accommodation to the Northern Cities Shift in Lansing, Michigan. Doctoral dissertation, Michigan State University.

Roeder, Rebecca V. 2010. Northern Cities Mexican American English: Vowel production and perception. American Speech 85(2): 163-184.

Rosenfelder, Ingrid, Joe Fruehwald, Keelan Evanini, and Jiahong Yuan.2014. FAVE (Forced Alignment and Vowel Extraction) Program Suite v1.2.2 10.5281/zenodo.22281.

Samare, Yadollah. 1985. Persian phonetics. Tehran: Iran University Press.

Sebastián-Gallés, Núria, and Salvador Soto-Faraco. 1999. Online processing of native and non-native phonemic contrasts in early bilinguals. Cognition 72(2): 111-23.

Sheikhbahaie, Masoud. 2020. A sociophonetic analysis of Farsi vowel systems among heritage speakers and immigrants of Persian ethnicity in Oklahoma. Toronto Working Papers in Linguistics, 42.

Tagliamonte, Sali A. 2011. Variationist sociolinguistics: Change, observation, interpretation: John Wiley $\&$ Sons.

Thomas, Erik. R. 1997. A rural/metropolitan split in the speech of Texas Anglos. Language Variation and Change 9: 309-332.

Thomas, Erik. R. 2001. An acoustic analysis of vowel variation in new world English. Durham: Duke University Press.

Thomas, Erik. R. 2008. Rural Southern white accents. In Varieties of English - the Americas and the Caribbean, ed. E.W. Schneider, 87-114. Mouton de Gruyter: Berlin.

Thomas, Erik. R. 2018. What a swarm of variables tells us about the formation of Mexican American English. Language Variety in the New South: Contemporary Perspectives on Variation and Change: 274-288.

Thomas, Erik R., and Tyler Kendall. 2007. NORM: The vowel normalization and plotting suite. Online Resource. lvc.uoregon.edu/norm/index.php

Thomason, Sarah Grey, and Terrence Kaufman. 1988. Language contact, creolization, and genetic linguistics. Berkeley: University of California Press.

Tillery, Jan, and Guy Bailey. 2008. The urban South: phonology. In Varieties of English - the Americas and the Caribbean, ed. E.W. Schneider, 115-128. Berlin: Mouton de Gruyter.

Trudgill, Peter. 1986. Dialects in contact. Oxford/ New York: Blackwell. 
Van Coetsem, Frans. 2016. Loan phonology and the two transfer types in language contact. Dordrecht: Foris/Berlin: Mouton de Gruyter.

Herzog, Marvin I., William Labov, and Uriel Weinreich. 1968. Empirical foundations for a theory of language change. In Directions for historical linguistics, ed. Winfred P. Lehmann and Yakov Malkiel, 95-188. Austin: University of Texas Press.

Weinreich, Uriel. 1953. Languages in contact: Findings and problems. The Hague: Mouton.

Weirich, Phillip. 2013. A study of the pin/pen merger in Oklahoma. Master's thesis, Oklahoma State University

Windfuhr, Gernot L. 2011. Persian grammar: History and state of its study. The Hague: Mouton.

Wolfram, Walt. 1974. The relationship of white southern speech to vernacular black English. Language 50: 498-527.

Yarmohammadi, Lotfollah. 1985. An introduction to phonetics (in Persian). Tehran: Iran University Press.

Yeni-Komshian, Grace H., James E. Flege, and Serena Liu. 2000. Pronunciation proficiency in the first and second languages of Korean-English bilinguals. Bilingualism: Language and cognition 3(2): 131149.

\section{Appendix A: RODEO Reading Passage}

Mike was planning to throw a party on Tuesday night. His wife had pinned a list to the bulletin board and he decided to check it one more time before he went shopping. He had already bought plenty of stuff to drink and he had enough plates and cups. He remembered that his brother Don was going to bring some fish he'd caught and maybe put them on the grill. Mike thought he should get some chips, pretzels, and a few other snacks to start the meal. He looked around to see if he had anything sweet, but then it dawned on him that his friend Cindy was baking a cake. When he looked in the cupboard he saw that he was out of coffee. He grabbed a pen, wrote it down on his list, and hoped it was on sale. Then he went to the garage, got his truck, and went to the Wal-Mart.

\section{Appendix B: RODEO Word List}

\begin{tabular}{|c|c|c|c|c|c|}
\hline tree & soda & cut & dawn & heat & had \\
\hline pig & head & heed & hood & mesh & business \\
\hline Wendy & shrimp & send & boat & thick & shop \\
\hline hayed & strike & shoot & mat & strength & \\
\hline day & Houston & knife & hem & peel & \\
\hline every & Floyd & hook & fish & talker & \\
\hline jab & seven & forty & wasn't & Tuesday & \\
\hline tin & with & push & where & loan & \\
\hline hud & hock & hawed & cool & hoed & \\
\hline cob & hod & out & ten & boy & \\
\hline saw & cloud & brother & bet & lie & \\
\hline hoe & sinned & lied & pawed & those & \\
\hline good & Steve & chewed & fail & Don & \\
\hline Who'd & trade & then & $\operatorname{dim}$ & hug & \\
\hline hawk & sang & heard & ate & hid & \\
\hline chew & sing & windy & Ruth & garage & \\
\hline duty & measure & happy & wash & How & \\
\hline
\end{tabular}




\section{Appendix C: Network relations questions}

1. What percentage of the people from the following groups do you have as close friends and associates?
A. European-Americans
B. Persian-Americans
C. Iranians

2. What percentage of your Persian-American friends and associates live in the following states:

A. Oklahoma

B. California

3. What do you usually do when you have spare time?

4. Is Oklahoma a good place to grow up? Why or why not?

5. Have you ever wanted to live somewhere else? Why? Where?

6. Talk about your heritage a little bit. Do you feel proud to be Persian-American? What term do you use to describe yourself? As a Persian-American, how comfortable do you feel living in Oklahoma?

\section{Appendix D: Cultural practice questions}

1. What percentage of the food you eat is of the following types?
A. Persian
B. American

2. What percentage of your home decor is of the following themes?
A. Persian
B. American

3. What percentage of the movies you watch are in the following languages?
A. Persian
B. English

4. What percentage of the music you listen to are in the following languages?
A. Persian
B. English 